\title{
Multienzyme Super-Dosing in Broiler Chicken Diets: The Implications for Gut Morphology, Microbial Profile, Nutrient Digestibility, and Bone Mineralization
}

\author{
Jacoba Madigan-Stretton ${ }^{1,2}$, Deirdre Mikkelsen ${ }^{1}\left(\mathbb{D}\right.$ and Elham Assadi Soumeh ${ }^{1, *(1)}$ \\ 1 School of Agriculture and Food Science, Gatton Campus, University of Queensland, Gatton, \\ QLD 4343, Australia; j.madiganstretton@uq.net.au (J.M.-S.); d.mikkelsen@uq.edu.au (D.M.) \\ 2 Bioproton Pty Limited, Acacia Ridge, QLD 4110, Australia \\ * Correspondence: e.assadisoumeh@uq.edu.au; Tel.: +61-7-5460-1308
}

check for updates

Citation: Madigan-Stretton, J.; Mikkelsen, D.; Soumeh, E.A. Multienzyme SuperDosing in Broiler Chicken Diets: The Implications for Gut Morphology, Microbial Profile, Nutrient Digestibility, and Bone Mineralization. Animals 2021, 11, 1. https://dx.doi.org/10.3390/ ani11010001

Received: 22 November 2020 Accepted: 16 December 2020 Published: 22 December 2020

Publisher's Note: MDPI stays neutral with regard to jurisdictional claims in published maps and institutional affiliations.

Copyright: () 2020 by the authors. Licensee MDPI, Basel, Switzerland. This article is an open access article distributed under the terms and conditions of the Creative Commons Attribution (CC BY) license (https: / / creativecommons.org/ licenses/by/4.0/).
Simple Summary: Optimizing the gut microbial community and morphometrical traits has become an increasingly prominent area of research due to recent evidence that suggests gut health and functionality affects the production performance of broilers. Creating a diverse microbial population can increase the nutrient digestibility of feed, as the microbes can break down a large portion of macromolecules and convert them into bioavailable substrates to be utilized by the host. A diverse microbiome can be promoted by a variety of additives, including feed enzymes. This study investigated the impact of the application of super-dosing multienzymes on gut morphology, microbial profile, nutrient digestibility, and bone mineralization in broiler chickens. Results found that super-dosing multienzymes improved nutrient digestibility, maintained a diverse microbial population, and tended to increase the overall villi morphology. Bone mineralization was not affected by increasing multienzyme doses. Additionally, the present study found three bacteria that were unique to multienzyme inclusion at a super-dose level.

Abstract: Optimizing gut health has a large impact on nutrient digestibility and bioavailability, and super-dosing feed enzymes may be one solution to achieve this. A 42-day grow-out trial was conducted using 192 Ross 308 broilers to determine if super-dosing Natuzyme at $0 \mathrm{~g} / \mathrm{t}, 350 \mathrm{~g} / \mathrm{t}$, $700 \mathrm{~g} / \mathrm{t}$, and $1000 \mathrm{~g} / \mathrm{t}$ dose rates could improve the gut morphology, alter the cecal microbial profile, enhance bone mineralization, and improve nutrient digestibility of a wheat-corn-soybean diet (six replicates per treatment, eight birds per pen). One bird per pen was slaughtered at day 42 and gut morphology, cecal microbial profile, and nutrient digestibility were studied. The addition of enzymes tended to increase the villus height in the duodenum, villus height, width, and crypt depth in the jejunum, and villus width and the number of goblet cells in the ileum. Microbial profiling revealed diverse communities; however, they did not significantly differ between treatment groups. Yet, $700 \mathrm{~g} / \mathrm{t}$ Natuzyme promoted microbes belonging to the genus Romboutsia and Ruminococcus gauvreauii, while $1000 \mathrm{~g} / \mathrm{t}$ Natuzyme promoted Barnesiella species. The nutrient digestibility demonstrated a significant improvement in all enzyme doses compared to the control. In conclusion, based on the outcomes of this study, a dose rate of $700 \mathrm{~g} / \mathrm{t}$ Natuzyme is recommended to improve gut morphology and nutrient digestibility, and promote unique microbes which aid in feed efficiency.

Keywords: bone mineralization; broiler chicken; gut morphology; gut microbiota; Natuzyme super-dosing

\section{Introduction}

The gastrointestinal tract is composed of an intricate ecosystem of microbiota which plays a fundamental role in nutrient digestion and absorption. The gut microbial profile has a significant impact on overall poultry health, immune response, and growth performance. The resident microbiota is regulated by unique host-microbial and microbial-microbial 
interactions which have developed through evolution [1,2]. However, the microbiota is strongly influenced by dietary composition, environmental factors, and the health status of the animal [3]. The gastrointestinal tract is the interface between the outside world and the internal body, making it a defensive barrier against harmful pathogens and foreign bodies. Promoting good gut health is fundamental to maintaining a high-performing flock, as healthy birds can devote the majority of their energy uptake to production rather than combating disease. Good gut health results in improved feed conversion ratio, increased weight gain, decreased mortality, and an increased performance index, thus, it is imperative for farmers to promote and maintain good gut health in their flock [3].

Previously, livestock gut health, particularly in poultry, has been modulated by the inclusion of antibiotics in the diets, as they are able to control pathogens through direct manipulation of the gastrointestinal tract microbiota [4]. This manipulation can reduce competition between existing microbes due to a decrease in diversity and abundance, resulting in improved digestion, absorption, and metabolism of essential nutrients [4]. However, over time, animals have become significantly less responsive to antibiotics, and the dose rate has had to increase by 11 times since the initial implementation of antibiotics as growth promotors [5]. The increasing dosage is synonymous with an increase in antimicrobial resistance, which has become a global emerging threat to public health Therefore, a movement to eliminate antibiotics from livestock production has emerged. Although this is a necessary change, it presents challenges to farmers who are required to seek alternative additives that will promote gut health and production performance.

Recent literature has deemed enzymes to be an advantageous additive for gut health promotion in broilers [6]. From hatching to day 7 of life, the broiler gastrointestinal tract undergoes significant morphological changes, which are heavily influenced by diet. In young birds, the gastrointestinal tract is short, and there is rapid passage rate and limited digestion due to the underdevelopment of villi, and a lack of endogenous digestive enzymes secreted. As the bird approaches 2 weeks of age, the secretion and activity of digestive enzymes increase, which improves nutrient utilization and gut functionality. However, the endogenous and mucosal enzymes have different developmental timetables, which has a direct influence on feed digestibility. Exogenous enzymes are used in animal feed to facilitate the breakdown of antinutritional factors, such as dietary fiber and phytic acid, lower the digesta viscosity, prevent over-fermentation and diarrhea, improve the nutritive value of the feed, and improve production performance and feed efficiency of the animal [7]. Research has demonstrated that the addition of exogenous protease was able to modify the gut morphology, such as increasing villus length and supplementing the lack of endogenous enzyme secretion [8]. In addition, the addition of exogenous protease allows for a reduction in the amount of diet crude protein with no adverse effect on the feed intake, weight gain, and survivability rates in broilers [9].

Super-dosing multienzymes is an emerging practice that is thought to improve nutrient digestibility through synergistic enzyme action. As different enzymes target different compounds, multienzymes should be more effective than single-strain enzymes, as there will be more nutrients acquired from the diet. Poultry naturally produce a plethora of digestive enzymes, however, the digestive process with endogenous enzymes alone still leaves up to $25 \%$ of feed undigested due to the presence of antinutritive factors, which the animal cannot combat with endogenous enzymes [7]. There is substantial literature surrounding the effective use of single-strain enzymes, such as phytase, however, publications on multienzyme super-dosing are lacking. Although the literature surrounding this topic is scarce for broilers, Hamdi et al. [10] found that super-dosing phytase improved meat yield and feed conversion ratio (FCR). Furthermore, a review by Cowieson et al. [11] concluded that there may be considerable opportunity to improve production performance by super-dosing phytase, however, the exact mechanism is still unknown. Therefore, it is important to investigate the effects of super-dosing multienzymes to fill the knowledge gap surrounding the effects and mode of action of this nutritional strategy. 
It is hypothesized that super-dosing multienzymes from day 0 post-hatch can improve gut morphology and nutrient digestibility due to the increased bioavailable nutrient content, and promote a diverse and stable microbial community, which will ultimately improve flock performance.

\section{Materials and Methods}

All experimental procedures involving the use of animals complied with the "Australian Code of Practice for the Care and Use of Animals for Scientific Purposes" and were approved by the Animal Ethics Committee of the University of Queensland. The animal ethical certificate was obtained prior to the commencement of this trial (number: SAFS/510/18/BIOPROTON).

\subsection{Birds and Experimental Design}

One-hundred and ninety-two 1-day-old mixed-gender broiler chickens (Ross 308) were purchased from a commercial hatchery (Woodlands Hatchery, QLD) and transferred to the isolation shed, a closed shed with isolated cold room panels at the Queensland Animal Science Precinct (QASP) facility at Gatton Campus, University of Queensland. The birds were weighed and randomly assigned to 1 of 4 experimental groups in a randomized complete block design (RCBD). Each experimental diet was fed to 6 replicate pens $\left(1 \times 1 \mathrm{~m}^{2}\right)$ with 8 birds in each $(n=48$ per experimental group). The experimental diets (Table 1) were in mash form and included a standard wheat-corn-soybean diet (control) with 4 enzyme inclusion levels $(0,350,700$, and $1000 \mathrm{~g} /$ ton). No antibiotics were added as growth promotors. All nutrients were supplied to meet nutrient recommendations (Table 2). The enzyme Natuzyme (Bioproton Pty. Ltd. QLD, Acacia Ridge, Australia) is a multienzyme blend that includes phytase, xylanase, cellulase, amylase, protease, betaglucanase, and mannanase at specific activities (Table 3), currently recommended at $350 \mathrm{~g} / \mathrm{t}$ by the manufacturer. The birds had ad libitum access to feed and water for the entire trial period. As per standard procedure, the grow-out period was divided into 3 phases (starter diet: day 1-14; grower diet: day 14-28; finisher diet: day 28-42) and nutrient levels were adjusted accordingly as per Ross 308 guidelines. On day 35, a natural indigestible and inert marker, acid insoluble ash, was added at a level of $0.2 \%$ to each experimental diet as a dietary digestibility marker. The lighting program, temperature, and humidity followed the Ross 308 guidelines. The lighting program provided $23 \mathrm{~h}$ of light at an 30-40 lux intensity and $1 \mathrm{~h}$ dark (less than 0.4 lux) for the first 7 days and a minimum of $4 \mathrm{~h}$ of darkness and a light period of 10 lux intensity after 7 days. The temperature was set at $32{ }^{\circ} \mathrm{C}$ and $40 \%$ relative humidity for the first 7 days and there was a $2{ }^{\circ} \mathrm{C}$ reduction per week after 7 days until the temperature reached $24^{\circ} \mathrm{C}$ at 27 days and $40 \%$ relative humidity. The temperature and relative humidity were maintained until the end of the trial.

At the end of the experiment, one bird with a body weight (BW) similar to the mean BW of the pen was euthanized by cervical dislocation and eviscerated to collect gut tissue for gut morphology, ileal digesta for nutrient digestibility, cecal content for microbial profile, and bone samples for bone mineralization studies.

\subsection{Gut Morphology}

The gastrointestinal tracts from the base of the gizzard down to the rectum were dissected, and sections $(\sim 1 \mathrm{~cm})$ were cut from the mid-regions of the duodenum, jejunum, ileum, and cecum, flushed with distilled water, and immersed in 10\% formalin solution. Fixed tissues were then loaded into appropriately sized cassettes for further gut histo-morphological analysis. Each fixed intestinal tissue sample was dipped in wax and a $5 \mathrm{~mm}$ section was cut and embedded in paraffin (Medite TES Valida embedding station). Embedded intestinal segments were cut at a thickness of $6 \mu \mathrm{m}$ (Leica semi-automated RM2245 rotary microtome, Leica Microsystems, VIC, Melbourne, Australia) and mounted onto slides. Then slides were stained by hematoxylin and eosin (HE), dried in the oven overnight, and cleaned to be scanned by light microscopy. The slides were scanned by 
an Aperio ScanScope XT (Leica Microsystems, VIC, Melbourne, Australia) and studied for the villus height, crypt depth, villus width, and the number of goblet cells. Then, the villus surface area was calculated and the villus height to crypt depth ratio measured.

Table 1. Ingredient composition of the experimental diets ${ }^{1}$.

\begin{tabular}{cccc}
\hline Diet Composition (\%) & Starter (1-14 d) & Grower (15-28 d) & Finisher (29-42 d) \\
\hline Wheat & 40.00 & 40.00 & 45.00 \\
Corn & 20.47 & 20.00 & 21.01 \\
Soybean meal & 29.83 & 29.36 & 23.81 \\
Soybean oil & 4.27 & 5.89 & 5.84 \\
L-Lysine HCL & 0.49 & 0.35 & 0.34 \\
DL-Methionine & 0.41 & 0.34 & 0.31 \\
L-Threonine & 0.26 & 0.18 & 0.16 \\
Limestone & 1.52 & 1.39 & 1.26 \\
Mono-calcium phosphate & 1.74 & 1.51 & 1.32 \\
Sodium bicarbonate & 0.32 & 0.25 & 0.25 \\
Salt & 0.15 & 0.20 & 0.20 \\
Vitamin/Mineral premix & 0.50 & 0.50 & 0.50 \\
Coccidiostat & 0.05 & 0.05 & 0.00 \\
\hline
\end{tabular}

${ }^{1}$ Natuzyme was added at 0, 350, 700, and $1000 \mathrm{~g} /$ ton dose rates, in each diet for the starter, grower, and finisher phases; ${ }^{2}$ Lysine hydrochloric acid.

Table 2. Calculated and analyzed nutrient composition of experimental diets.

\begin{tabular}{cccc}
\hline Diet Composition (\%) & Starter (1-14 d) & Grower (15-28 d) & Finisher (29-42 d) \\
\hline Calculated composition & & & \\
ME $^{1}(\mathrm{MJ} / \mathrm{kg})$ & 11.92 & 12.34 & 12.55 \\
Crude protein $(\%)$ & 21.00 & 20.50 & 18.50 \\
SID $^{2}$ Lysine $(\mathrm{g} / \mathrm{kg})$ & 12.80 & 11.50 & 10.20 \\
SID Met + Cys $(\mathrm{g} / \mathrm{kg})$ & 9.50 & 8.70 & 8.00 \\
SID Threonine $(\mathrm{g} / \mathrm{kg})$ & 8.60 & 7.70 & 6.80 \\
Calcium $(\mathrm{g} / \mathrm{kg})$ & 9.60 & 8.70 & 7.80 \\
Avail. phosphorous $(\mathrm{g} / \mathrm{kg})$ & 4.80 & 4.35 & 3.90 \\
Sodium $(\mathrm{g} / \mathrm{kg})$ & 1.60 & 1.60 & 1.60 \\
Analyzed composition & & & \\
Dry matter $(\mathrm{g} / \mathrm{kg})$ & 94.95 & 94.66 & 94.84 \\
Crude protein $(\%)$ & 20.03 & 18.20 & 79.59 \\
Crude fat $(\mathrm{g} / \mathrm{kg})$ & 61.11 & 77.00 & 23.99 \\
Crude fiber $(\mathrm{g} / \mathrm{kg})$ & 24.84 & 24.57 & 8.00 \\
Calcium $(\mathrm{g} / \mathrm{kg})$ & 11.90 & 10.40 & \\
\hline
\end{tabular}

${ }^{1}$ Metabolizable energy. ${ }^{2}$ Standardized ileal digestible.

Table 3. Enzyme activity levels in Natuzyme product.

\begin{tabular}{cc}
\hline Natuzyme Components & Enzyme Activity (u/g) \\
\hline Xylanase & 10,000 \\
b-Glucanase & 700 \\
Phytase & 1500 \\
Alpha-amylase & 400 \\
Cellulase & 6000 \\
Protease & 700 \\
Mannanase & 400 \\
\hline
\end{tabular}

Villus height was measured from the tip of the villus to the crypt between individual villi. Crypt depth was measured from the valley between the bases of the villi to the submucosa. Villus width was calculated from the mean value of villus width at one-third and villus width at two-thirds of the height of the villus. The area between 4 villi was 
used from 3 cuts per sample to count the number of goblet cells. The average of the 3 measurements was then reported as the number of goblet cells per surface area.

\subsection{DNA Extraction and 16S rRNA Gene Amplicon Sequencing}

Cecal content samples were collected from 1 bird per pen at 42 days of age, postmortem. Digesta from the cecum was collected into a $10 \mathrm{~mL}$ tube. Dissecting instruments were cleaned with $70 \%$ ethanol after use on each bird. Samples were put on ice immediately and stored at $-20^{\circ} \mathrm{C}$ prior to DNA extraction.

For each poultry digesta sample, $50 \mathrm{mg}$ was transferred into a sterile $2 \mathrm{~mL}$ screw-cap tube containing sterile $0.1 \mathrm{~mm}$ and $1.0 \mathrm{~mm}$ zirconia beads (total weight $0.4 \mathrm{~g}$; ratio 1:1). Microbial cell lysis was achieved by bead beating in a Qiagen TissueLyser II (Qiagen, Hilden, Germany; $30 \mathrm{~Hz}, 60$ s, 1 repetition conditions), for total genomic DNA (gDNA) extraction. Post lysis, tubes were left for $2 \mathrm{~min}$, for phase separation of the lysate, and each sample supernatant $(\sim 600 \mu \mathrm{L})$ was then processed for gDNA extraction and purification using the Maxwell 16 blood DNA purification kit (Promega, AS1010, Madison, WI, USA) and the automated Maxwell 16 MDx instrument (Promega, Alexandria NSW, Australia), according to the manufacturer's instructions. The instrument was set to standard elution volume (SEV) mode and the gDNA eluted into $300 \mu \mathrm{L}$ of elution buffer. Thereafter, the gDNA samples were quantified and purity verified with the NanoDrop 1000 spectrophotometer (Thermo Scientific, Brisbane, Australia), and subsequently submitted to the Australian Centre for Ecogenomics (ACE; the University of Queensland, Brisbane, Australia) for amplicon sequencing.

The variable region of the 16S rRNA gene was amplified between the V6 and V8 regions, using the universal forward and reverse primer pair of 926F (5'-TCG TCG GCA GCG TCA GAT GTG TAT AAG AGA CAG AAA CTY AAA KGA ATT GRC GG-3') and 1392wR (5'-GTC TCG TGG GCT CGG AGA TGT GTA TAA GAG ACA GAC GGG CGG TGW GTR C $\left.-3^{\prime}\right)$. The gDNA was fragmented and tagged with specific index adapter sequences on both ends of the gDNA fragments using the Nextera XT DNA Library Preparation kit (Illumina, San Diego, CA, USA), enabling dual-indexed sequencing of pooled libraries. The libraries were pooled and sequencing was then carried out on a $2 \times 300 \mathrm{bp}$ V3 MiSeq sequencer (Illumina, San Diego, CA, USA). Post-sequencing, quality control, indexing, quantification, and normalization steps were carried out by the sequence provider.

\subsection{Bioinformatics Analysis}

Raw data files were provided by ACE as fasta files. Analysis of these sequencing files were carried out by using Quantitative Insight into Microbial Ecology 2 (QIIME2) [12]. Operational taxonomic units (OTUs) were assigned using the Greengenes 13_8 database [13], using a threshold setting of $97 \%$ sequence identity. These data were then normalized to relative abundance using cumulative sum scaling (CSS), a widely used method for normalizing microbial community composition data, and the data were also $\log 2$ transformed to account for the non-normal distribution of taxonomic count data, in Calypso Version 8.84 [14]. This software was also used to generate $\alpha$-diversity parameters, hierarchical clustering and principal coordinate analysis (PCoA) plots. To examine the alpha diversity parameters of each sample, rank tests including richness, evenness, Chao1 index, Shannon index, and Simpson's index were carried out. The richness examined the number of different OTUs present within each sample and the evenness was a measure of the relative abundance of the different OTUs making up the richness. Additionally, PCoA (beta diversity) was conducted based on Bray-Curtis distance metrics focusing on the top 20 OTUs, to explore how the overall microbiota composition differed across the 24 samples and four diets.

\subsection{Nutrient Digestibility}

Post-processing, the gastrointestinal tract was removed from the carcass. The ileal content was evacuated into a $10 \mathrm{~mL}$ O-ring tube and placed on ice and left in a $-20{ }^{\circ} \mathrm{C}$ 
freezer until freeze drying occurred. This process was repeated for all 24 birds. The sample was weighed pre-freeze drying and post-freeze drying to calculate dry matter. To determine the ash and organic matter content, $2 \mathrm{~g}$ of the sample were placed in a crucible and burned in a muffle furnace for $3 \mathrm{~h}$ at $500{ }^{\circ} \mathrm{C}$ [15], and it was calculated by the following equation:

$$
\begin{gathered}
\mathrm{Wt} \% \text { ash }=(\text { ashed sample }- \text { preashed sample }) * 100 \\
\text { Organic matter }=100-\mathrm{wt} \% \text { ash }
\end{gathered}
$$

To determine carbon, nitrogen, and sulfur content in the sample, $1 \mathrm{~g}$ of sample was placed into a ceramic boat in the Leco CNS 928 combustion analyzer (LECO Australia, NSW, Castle Hill, Australia) and analyzed.

The nutrient ileal digestibility was calculated using the following equation:

Nutrient apparent ileal digestibility $(\%)=[100-(\mathrm{Ni} \times \mathrm{Md}) /(\mathrm{Nd} \times \mathrm{Mi})] \times 100$

where Ni represents a concentration of the nutrient in ileal digesta; Md represents a dietary concentration of marker; $\mathrm{Nd}$ represents a dietary concentration of the nutrient under the study; and Mi represents the concentration of marker in ileal digesta [16].

\subsection{Bone Mineralization}

The meat was removed from the right tibia bone before freezing the bone samples for mineral analyses. The right tibia bone of 24 chickens were defrosted and broken into small pieces using pliers. The entire tibia bone was collected from the right leg of each broiler chicken at 42 days and cleaned of adhering tissue. Bones were dried to a constant weight at $105^{\circ} \mathrm{C}$, then burned to ash in a muffle furnace at $600{ }^{\circ} \mathrm{C}$. Ash was dissolved in concentrated $\mathrm{HCl}$ for mineral determination $(5 \mathrm{~mL}$ of $6 \mathrm{M}$ hydrochloric acid and $35 \mathrm{~mL}$ of distilled water), and the solution was filtered into a $250 \mathrm{~mL}$ glass bottle and made up to a final volume of $50 \mathrm{~mL}$ with distilled water. Thereafter, the $\mathrm{Ca}$ and $\mathrm{P}$ levels were measured using a Thermo iCAP 6000 series inductive coupled plasma (ICP) spectrophotometer (Thermo Electron Corporation, Str. Rivoltana, 20090 Rodana, Milan, Italy). The Ca and P composition ( $\mathrm{g} / \mathrm{kg}$ in ash) was calculated using iTEVA Analyst software (Cambridge, UK).

\subsection{Statistical Analysis}

Analysis of variance was performed on the least square means (LSM) values of the pens as an experimental unit using mixed models of SAS [17]. All values of $p \leq 0.05$ were deemed statistically significant, and all values of $0.05 \leq p \leq 0.1$ were considered a tendency. The reported LSM was separated using Tukey's post hoc test.

\section{Results}

Multienzyme actual activities for different Natuzyme dose rates were very close to the expected activities (Table 4).

Table 4. Natuzyme expected vs. actual activity at different dose rates.

\begin{tabular}{ccc}
\hline Natuzyme Dose Rate $(\mathbf{g} / \mathbf{t})$ & Expected Activity $(\mathbf{U} / \mathbf{g})$ & Experimental Value $(\mathrm{U} / \mathrm{g})$ \\
\hline 350 & 1.27 & 1.20 \\
700 & 2.54 & 2.51 \\
1000 & 3.63 & 3.59 \\
\hline
\end{tabular}

\subsection{Gut Morphology}

There were no significant effects in any of the gut morphological parameters when Natuzyme was added into the standard diet in increasing dose rates (Table 5). As the enzyme dose increased, the villus height in the duodenum $(p=0.06)$ and jejunum $(p=0.09)$ tended to increase. The increasing dose rate of Natuzyme also tended to increase crypt depth $(p=0.10)$ and villus width in the jejunum and ileum $(p=0.10)$. 
Table 5. The effects of Natuzyme dose rates on gut morphology of 42-day old broiler chickens.

\begin{tabular}{|c|c|c|c|c|c|c|}
\hline \multirow{2}{*}{ Parameter } & \multicolumn{4}{|c|}{ Experimental Diets } & \multirow{2}{*}{ SEM } & \multirow{2}{*}{$p$-Value } \\
\hline & Control & $350 \mathrm{~g} / \mathrm{t}$ & $700 \mathrm{~g} / \mathrm{t}$ & $1000 \mathrm{~g} / \mathrm{t}$ & & \\
\hline \multicolumn{7}{|l|}{ Duodenum } \\
\hline Villus height $(\mu \mathrm{m})$ & 956.32 & 995.36 & 1128.88 & 1204.45 & 98.57 & 0.06 \\
\hline Crypt depth $(\mu \mathrm{m})$ & 115.32 & 79.57 & 113.70 & 121.23 & 15.72 & 0.23 \\
\hline Villus width $(\mu \mathrm{m})$ & 1083.67 & 1084.41 & 1245.53 & 1132.29 & 125.57 & 0.78 \\
\hline $\mathrm{VH} / \mathrm{CD}^{1}$ & 9.12 & 13.02 & 10.63 & 11.14 & 1.78 & 0.50 \\
\hline $\begin{array}{l}\text { Number of goblet cells } \\
\text { Jejunum }\end{array}$ & 26.11 & 20.53 & 29.11 & 23.69 & 3.79 & 0.44 \\
\hline Villus height $(\mu \mathrm{m})$ & 808.41 & 668.62 & 916.56 & 892.61 & 80.20 & 0.09 \\
\hline Crypt depth $(\mu \mathrm{m})$ & 92.79 & 92.18 & 146.19 & 103.87 & 16.42 & 0.10 \\
\hline Villus width $(\mu \mathrm{m})$ & 1121.64 & 827.72 & 804.57 & 1106.53 & 112.22 & 0.11 \\
\hline $\mathrm{VH} / \mathrm{CD}$ & 9.51 & 6.81 & 6.94 & 9.04 & 1.47 & 0.38 \\
\hline $\begin{array}{c}\text { Number of goblet cells } \\
\text { Ileum }\end{array}$ & 17.94 & 18.03 & 14.06 & 15.78 & 3.87 & 0.87 \\
\hline Villus height $(\mu \mathrm{m})$ & 640.82 & 639.33 & 629.27 & 641.81 & 64.02 & 0.99 \\
\hline Crypt depth $(\mu \mathrm{m})$ & 111.61 & 107.93 & 116.65 & 118.98 & 25.65 & 0.99 \\
\hline Villus width $(\mu \mathrm{m})$ & 953.14 & 1063.70 & 1158.59 & 1192.81 & 147.04 & 0.10 \\
\hline $\mathrm{VH} / \mathrm{CD}$ & 6.62 & 6.73 & 6.63 & 6.38 & 1.17 & 0.99 \\
\hline Number of goblet cells & 13.67 & 14.89 & 17.17 & 17.17 & 2.13 & 0.14 \\
\hline
\end{tabular}

${ }^{1} \mathrm{VH} / \mathrm{CD}=$ villus height to crypt depth ratio. Data are the means \pm SEM of six replicates per treatment.

Anecdotal data revealed that several gut samples from birds fed with $1000 \mathrm{~g} / \mathrm{t}$ Natuzyme had blood observable on a macroscopic level (Figure 1).

\subsection{Microbial Community Diversity}

For all samples analyzed, following sequencing quality control, amplicon clustering, and taxonomic classification, a total of 949,364 sequence reads were obtained. Per sample, sequence reads ranged from a minimum of 17,209 to a maximum of 42,441, and clustered into 1103 OTUs. A rarefaction plot was generated indicating the total number of sequence reads and richness obtained per sample (Supplementary Material Figure S1). This allowed for the determination of whether the appropriate sequence depth was achieved per sample, thereby ensuring that the microbial community in each sample was robustly represented. The relative abundance of combined experimental groups is presented in Table 6. 


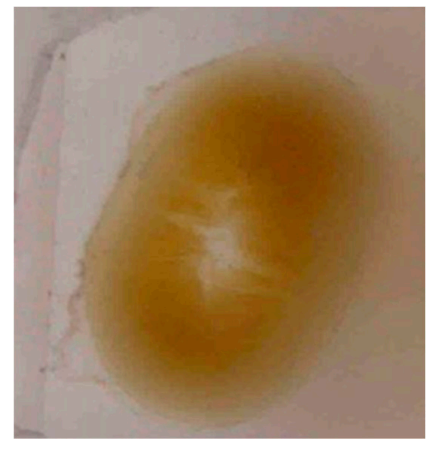

(a)

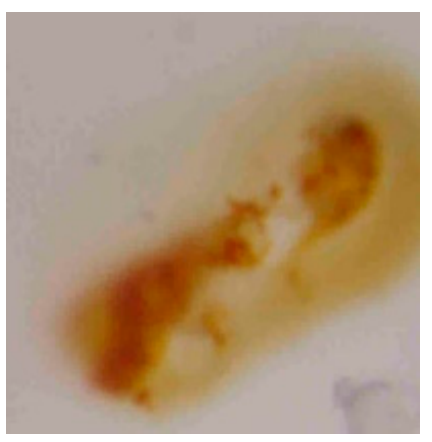

(d)

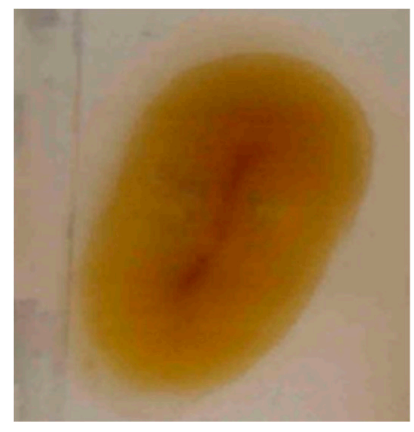

(b)

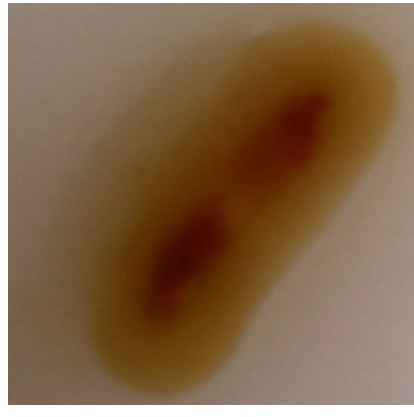

(e)

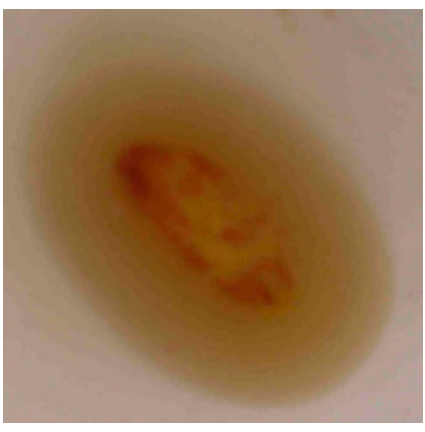

(c)

Figure 1. Bloodiness scale: (a) grade 1 (no blood present); (b) grade 2: thin lining of blood in the center of the gastrointestinal tract; (c) grade 3: patchy blood scattered throughout the center of the GIT; (d) grade 4: patchy, thick blood in the center of the GIT; (e) grade 5: thick, consistent blood throughout the GIT.

Table 6. Relative abundance of bacterial phyla (combined for all diets).

\begin{tabular}{cc}
\hline Phyla & Relative Abundance \\
\hline Firmicutes & $66.67 \%$ \\
Proteobacteria & $7.58 \%$ \\
Bacteroidetes & $6.06 \%$ \\
Actinobacteria & $6.06 \%$ \\
Other phyla & $<8 \%$ \\
\hline
\end{tabular}

Alpha diversity parameters including richness, evenness, Shannon index, Simpson's index, and Chao1 index were examined (Figure 2). Richness examined the number of different OTUs present within each sample (Figure 2A), while evenness measured the relative abundance of the different OTUs comprising the richness (Figure 2B). The results suggest that the microbial profiles in the digesta sampled from the poultry birds fed one of four experimental diets shared similar richness and evenness when compared, and these observations were not different $(p \geq 0.05)$. However, the Shannon indices observed in this study for all 24 samples were over 3 , indicative of the existence of a highly diverse microbiota per sample (Figure 2C), as Shannon index values above 3 are regarded as indicators of a diverse microbial community, in terms of richness and evenness [18]. Additionally, the Simpson's indices, which account for both the number of OTUs present and their relative abundance per sample, suggests that all samples had similar OTU diversity (Figure 2D). Chao1 index indicated no difference in OTU abundance between all the samples (Figure 2E). Thus, overall, the alpha diversity parameters indicate that the 
digesta sampled contained a highly diverse microbiota, which was similar in abundance across all 24 samples.

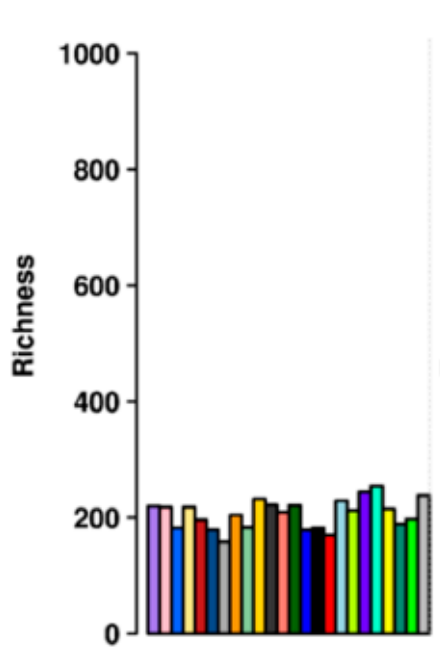

(A)

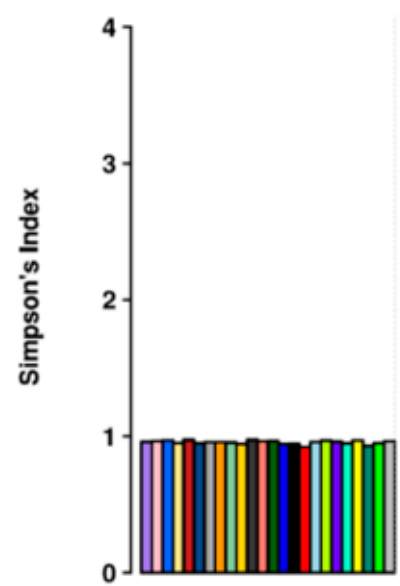

(D)

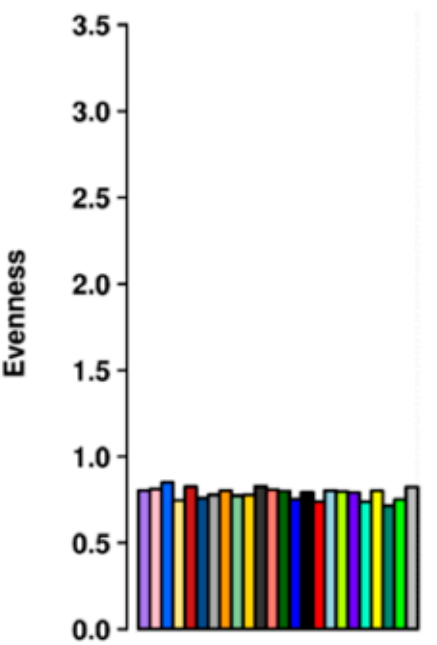

(B)

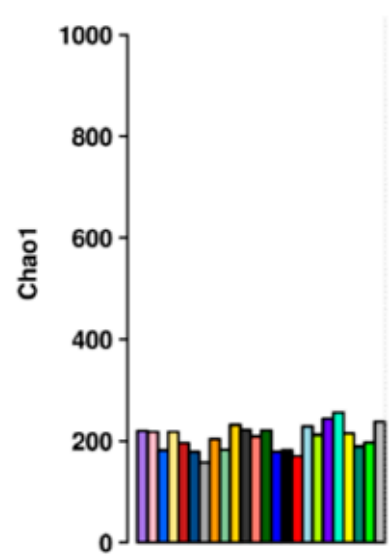

(E)

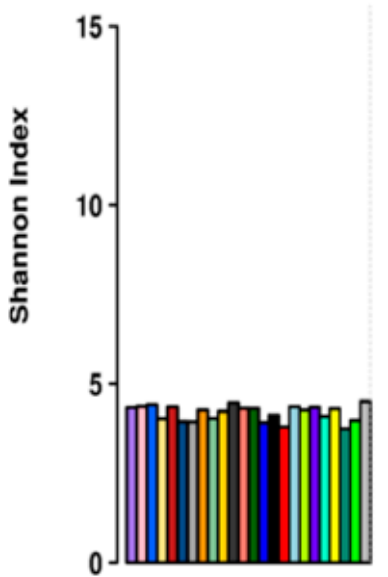

(C)

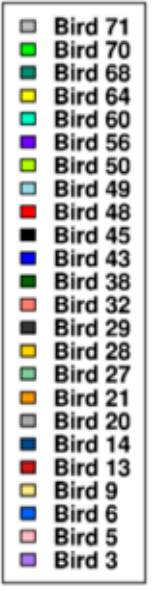

(F)

Figure 2. Alpha diversity parameters of caecum microbial profile: richness (A), evenness (B), Shannon index (C), Simpson's index (D), and Chao1 index (E) in 24 sampled birds (F).

The rank test indicates the number of different species present in each sample and the evenness rank test measures the relative abundance of the different species making up the richness, while the Shannon index accounts for both abundance and evenness of species present in each sample.

Analysis of the 20 most abundant phyla and genera present across all 24 samples (Figure $3 \mathrm{~A}, \mathrm{~B}$, respectively) indicates that no differences in the microbial diversity in terms of relative OTU abundance were observed between birds on the four treatment diets. No distinct grouping of microbial communities was revealed, with PCoA1 and PCoA2 covering $31 \%$ and $19 \%$ of the total microbiota, respectively (Figure 4 ). 


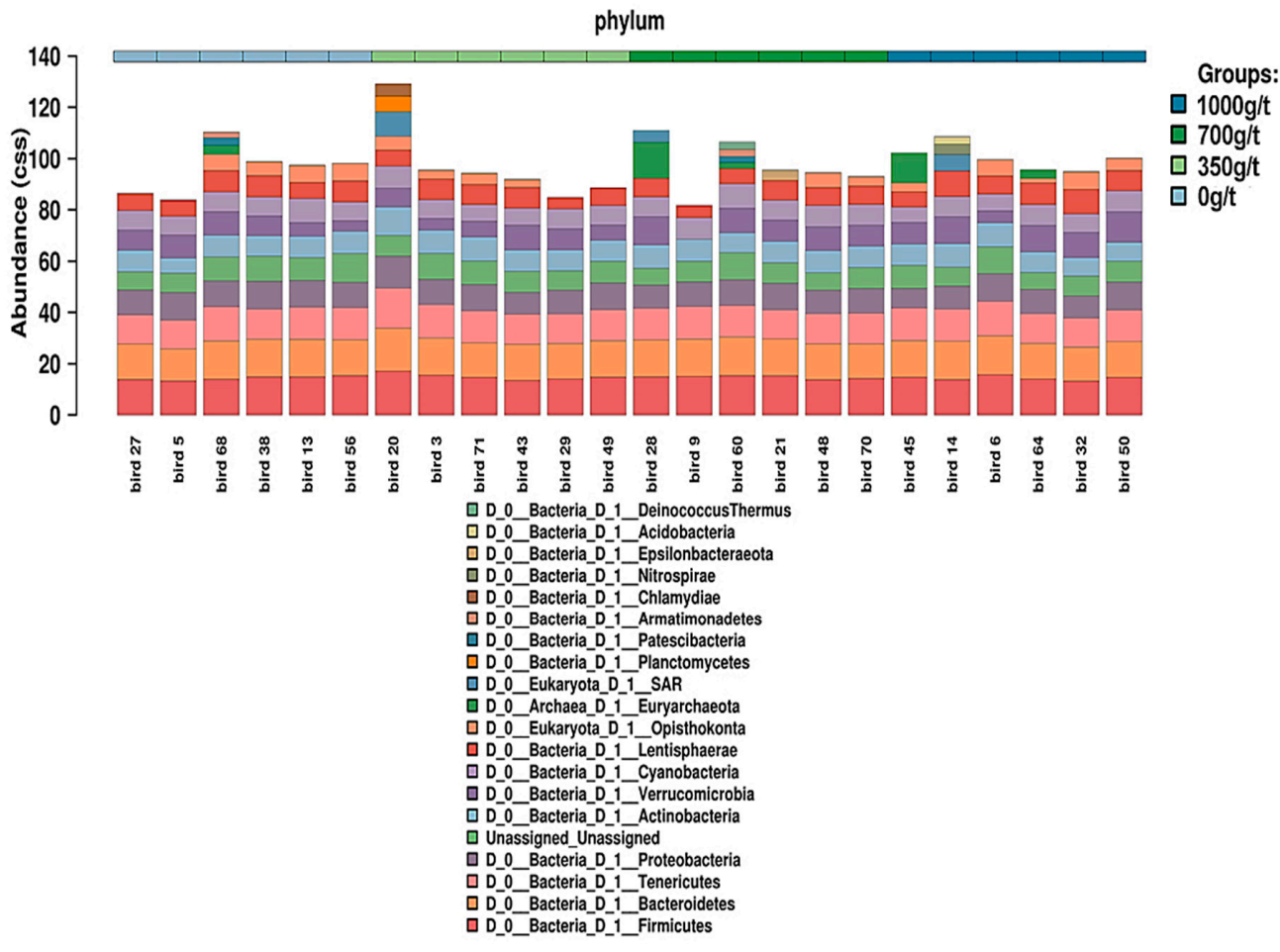

(A)

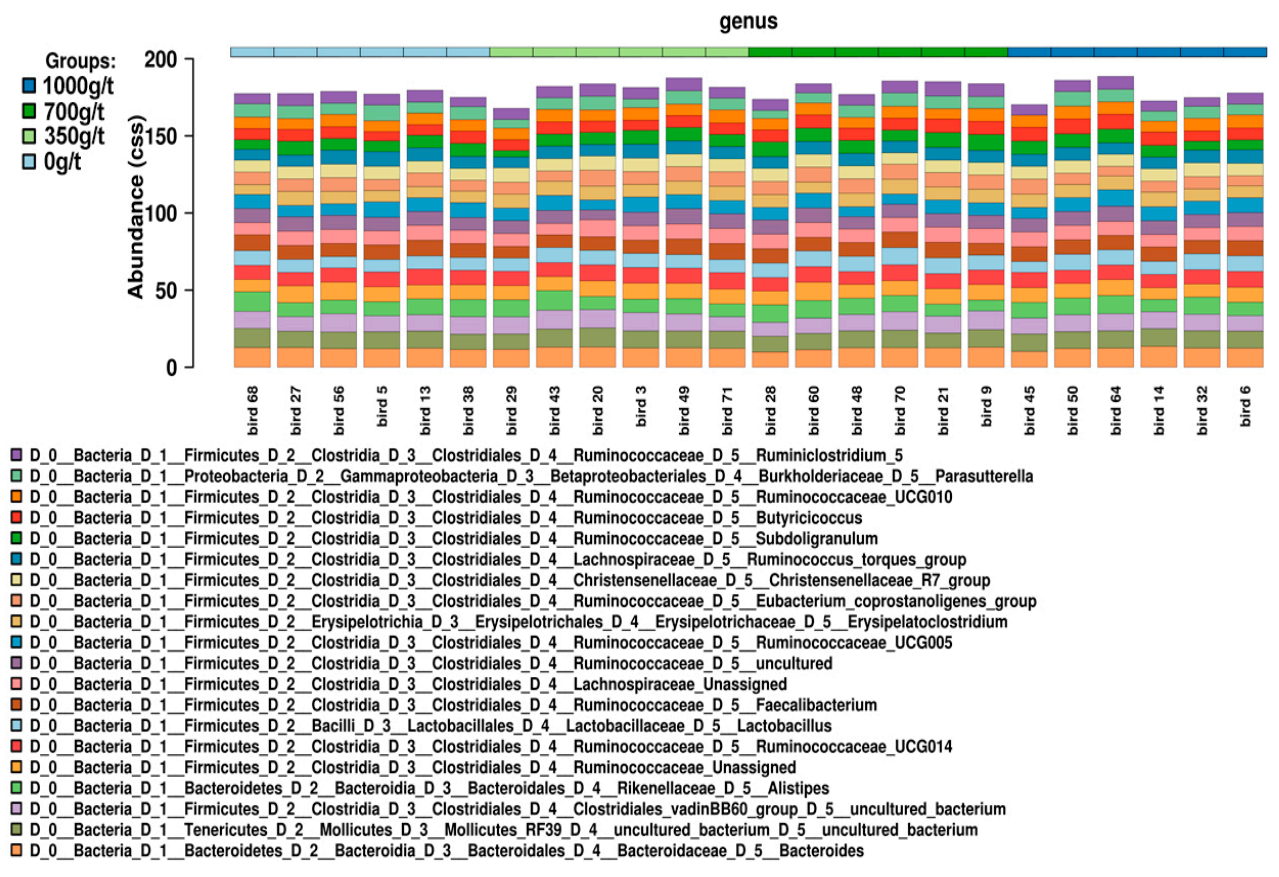

(B)

Figure 3. (A) Relative abundance of operational taxonomic units (OTUs) present in each poultry digesta sample, at a phylum level. (B) Relative abundance of OTUs present in each poultry digesta sample, at a genus level. 


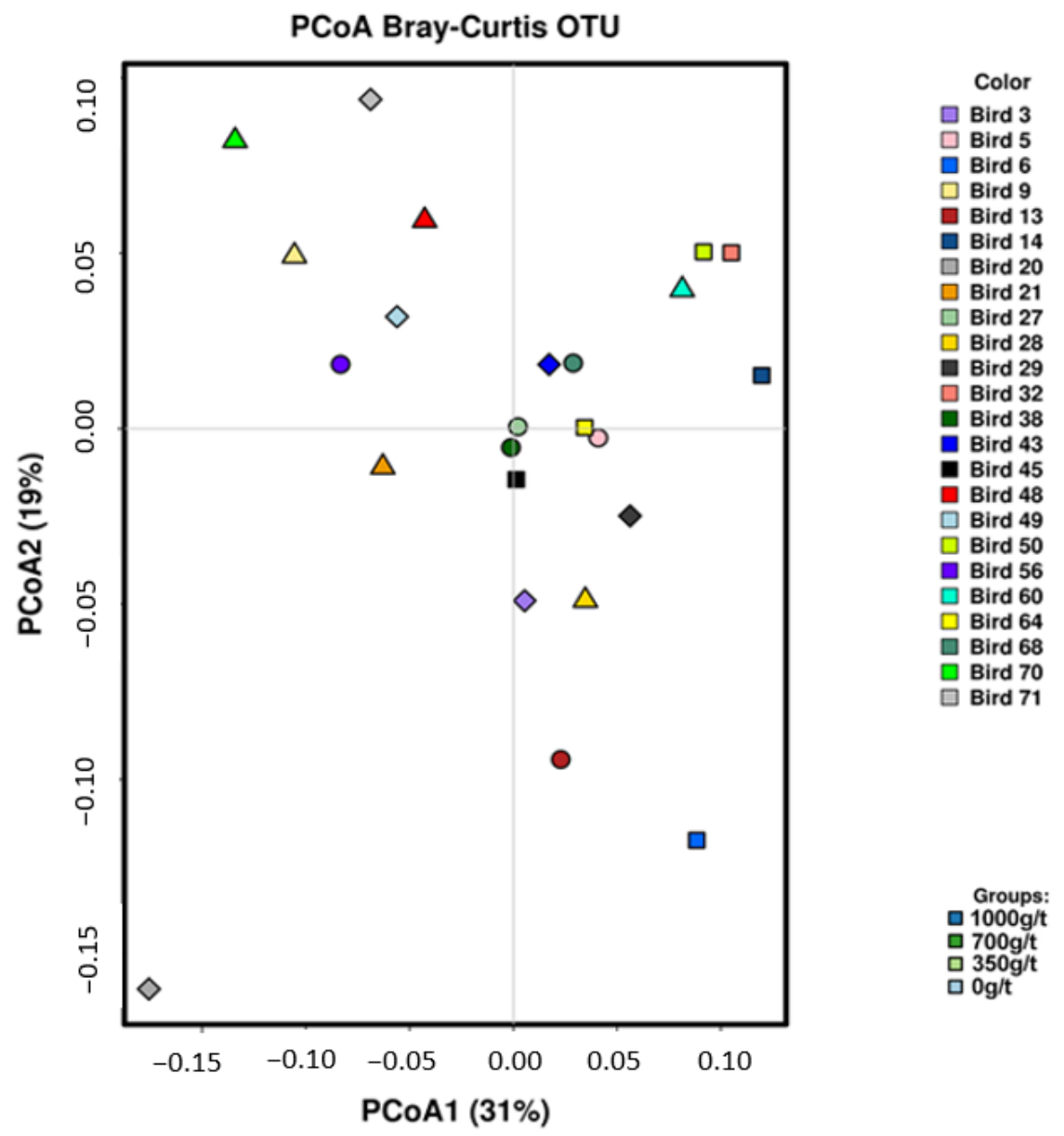

Figure 4. Principal coordinate analysis (PCoA) of microbiota based on Bray-Curtis distance for OTUs.

However, core microbiota analysis of the top 100 abundant genera revealed that 66 OTUs were core to all four diet treatments, yet only three appeared to be uniquely associated with $700 \mathrm{~g} / \mathrm{t}$ Natuzyme (two unique OTUs) and $1000 \mathrm{~g} / \mathrm{t}$ Natuzyme (one OTU) (Figure 5). Specifically, the OTUs related to the genus Barnesiella were identified to be unique to $1000 \mathrm{~g} / \mathrm{t}$ Natuzyme, while the genus Romboutsia and the microorganism Ruminococcus gauvreauii were identified to be unique to $700 \mathrm{~g} / \mathrm{t}$ Natuzyme.

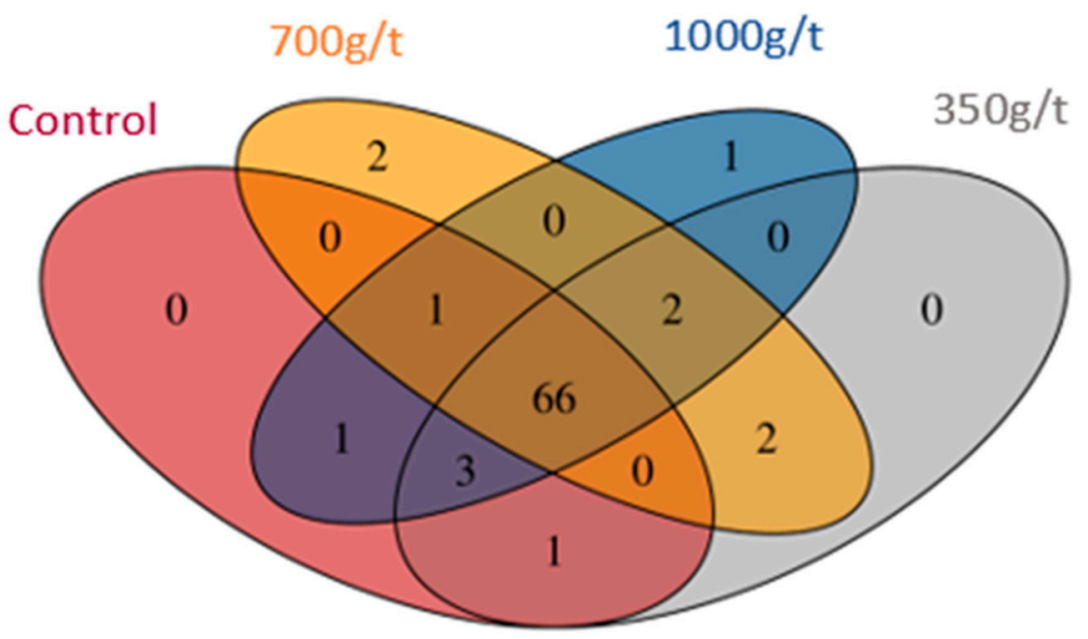

Figure 5. Core microbiota analysis was carried out at the genus level, including the top 100 relatively abundant OTUs present, to visualize the differences between the samples, based on diet groupings. 


\subsection{Nutrient Digestibility}

The effects of Natuzyme inclusion at different dose rates on nutrients' apparent ileal digestibility were highly significant (Table 7). As the dose rate increased, the nitrogen/crude protein and organic matter digestibility both increased $(p<0.001)$. In terms of nitrogen, 700 and $1000 \mathrm{~g} / \mathrm{t}$ Natuzyme revealed a significantly higher digestibility than the control (no enzyme) and $350 \mathrm{~g} / \mathrm{t}$, however, there is a general linear increase in digestibility as enzyme dose rate increases. In terms of organic matter, the experimental diets with Natuzyme included at all dose rates had a significantly higher digestibility than the control, however, 700 and $1000 \mathrm{~g} / \mathrm{t}$ of Natuzyme also had significantly higher organic matter digestibility than $350 \mathrm{~g} / \mathrm{t}$ of Natuzyme.

Table 7. Nutrient apparent ileal digestibility of 42-day-old broiler chickens fed with Natuzyme super-dosed diets.

\begin{tabular}{ccccccc}
\hline \multirow{2}{*}{ Parameter } & \multicolumn{4}{c}{ Experimental Diets * } & \multirow{2}{*}{ SEM } & \multirow{2}{*}{$p$-Value } \\
\cline { 2 - 5 } & Control & $\mathbf{3 5 0} \mathbf{~ g / t}$ & $\mathbf{7 0 0} \mathbf{~ g / t}$ & $\mathbf{1 0 0 0} \mathbf{~} / \mathbf{t}$ & & \\
\hline Nitrogen digestibility $\%$ & $51.0^{\mathrm{a}}$ & $56.7^{\mathrm{a}}$ & $70.5^{\mathrm{b}}$ & $74.9^{\mathrm{b}}$ & 2.4 & $<0.001$ \\
Organic matter $\%$ & $55.2^{\mathrm{a}}$ & $65.3^{\mathrm{b}}$ & $74.6^{\mathrm{c}}$ & $73.7^{\mathrm{c}}$ & 0.5 & $<0.001$ \\
\hline
\end{tabular}

* Values with different superscripts a-c are statistically different $(p<0.05)$. Data are the means \pm SEM

of six replicates per treatment.

\subsection{Bone Mineralization}

The effects of Natuzyme super-dosing on tibia bone mineralization are presented in Table 8. The mineral content of the tibia bone, including calcium, phosphorous, magnesium, potassium, sodium, sulfur, iron, and zinc, were not altered by the multienzyme dose rates.

Table 8. Bone mineralization of 42-day-old broiler chickens fed with enzyme super-dosed diets.

\begin{tabular}{ccccccc}
\hline \multirow{2}{*}{$\begin{array}{c}\text { Parameter, } \\
\mathbf{g} / \mathbf{k g} \text { ash }\end{array}$} & Control & $\mathbf{3 5 0} \mathbf{~} / \mathbf{t}$ & $\mathbf{7 0 0} \mathbf{~} / \mathbf{t}$ & $\mathbf{1 0 0 0} \mathbf{~} / \mathbf{t}$ & \multirow{2}{*}{ SEM } & $\boldsymbol{p}$-Value \\
\cline { 2 - 5 } & 42.05 & 42.23 & 42.97 & 41.84 & 0.75 & 0.73 \\
\hline Total ash & 374.16 & 373.42 & 376.14 & 373.35 & 1.94 & 0.42 \\
Calcium & 181.88 & 180.34 & 180.87 & 179.75 & 0.69 & 0.17 \\
Phosphorous & 7.78 & 7.61 & 7.49 & 7.54 & 0.08 & 0.08 \\
Magnesium & 4.89 & 4.78 & 4.54 & 4.58 & 0.43 & 0.64 \\
Potassium & 10.99 & 10.81 & 10.31 & 10.37 & 0.39 & 0.31 \\
Sodium & 1.70 & 1.59 & 1.37 & 1.83 & 0.47 & 0.40 \\
Sulfur & 241.91 & 242.76 & 230.81 & 212.80 & 12.76 & 0.32 \\
Iron & 267.55 & 271.38 & 275.46 & 264.82 & 6.48 & 0.68 \\
Zinc & ${ }^{*} \mathrm{~g} / \mathrm{kg}$ DM. Data are the means \pm SEM of six replicates per treatment. &
\end{tabular}

\section{Discussion}

\subsection{Gut Morphology}

The hypothesis of this trial was that multienzyme super-dosing would improve gut health via the breakdown of macromolecules, modulation of the broiler digestive physiology and manipulation of the microbial profile which would ultimately improve nutrient digestibility. The aim was to improve nutrient digestibility through enhancing the hydrolysis of macromolecules, improving gut development and increasing microbial diversity. This would enable a better surface area to volume ratio, thus a larger proportion of nutrients would be available and utilized by the bird, improving overall growth performance. The present experiment revealed no significant difference in villus height, crypt depth, VH/CD ratio, or goblet cell proliferation (Table 5) between any of the enzyme treatment groups. However, tendencies were observed that when the multienzyme dose rate increased, villi height and crypt depth increased in the duodenum and 
jejunum. Sharifi et al. [19] found that the addition of Natuzyme in corn-soybean diets significantly increased the villi height and improved nutrient digestibility. Ahmed et al. [20], Mazhari et al. [21], and Shakouri et al. [22] were in agreement, as they found that the inclusion of multienzymes significantly increased villus height and crypt depth, however, these were not super-dosed. However, Teirlynck et al. [23] demonstrated that including wheat in a ration evoked mucosal damage and villi fusion, which was typical of an inflammatory bowel condition. The standard diet formulation used in the present study contained approximately $40-45 \%$ wheat, which may have been a causative factor in the lack of significant difference between treatment groups and the presence of inflamed tissue (Figure 1).

The macroscopic gut samples did show observable differences between treatment groups regarding the presence of blood. Due to the variation, a scale (bloodiness scale) was created (Figure 1). Grade 4-5 necrotic tissue was recorded for a multitude of samples with the $1000 \mathrm{~g} / \mathrm{t}$ enzyme level, however, in only a small number was grade 4-5 bloodiness observed for lower enzyme dose rates. It is hypothesized that the protease concentration in the $1000 \mathrm{~g} / \mathrm{t}$ dose rate was too high for the bird to process, and accompanied by the endogenous protease excretion, may have begun digesting the gut wall. It was initially suspected that the presence of blood and necrotic tissue could also be due to a bacterial infection of the gut, however, upon completion of microbial profiling, it was disproved. This has not been recorded previously in the literature, so further investigation is required.

\subsection{Microbial Community Diversity}

Literature regarding super-dosing multienzyme effects on broiler intestinal microbiota is scarce, therefore, this study aimed to identify changes in the cecal microbial profiles influenced by multienzyme super-dosing, as improving nutrient availability will alter the abundance of specific bacteria as their food source has increased. The results of the present study highlight no differences in microbial diversity amongst all treatment groups, with no significant prevalence $(p<0.05)$ of any bacterial species being associated with a specific Natuzyme dose rate. These findings are supported by Lourenco et al. [24], who investigated the change in excreta microbial profiles in relation to protease and protein content in the diet. It was found that microbial richness was overall not changed in terms of observed OTUs and Chao1 index due to diet. Similar to the outcomes of the present trial, the Shannon index reported by Lourenco et al. [24] displayed no difference with enzyme inclusion, indicating a similar microbial profile across all treatment groups, in terms of species and richness.

As shown in Table 6, the relative abundance of bacteria was predominantly from the phylum Firmicutes, followed by Proteobacteria, Bacteroidetes, Actinobacteria, and other phyla. This trend has been also reported by Lourenco et al. [24] and Danzeisen et al. [25], with both finding Firmicutes as the predominant phylum in the chicken cecum content. Figure 5 reveals that of the 79 identified taxa, three were unique, 10 panned across several treatment groups, and the remaining 66 were core to all treatment groups. This indicates a relatively homogenous microbial pool across all treatment groups, which infers that altering multienzyme concentration alone does not influence microbial profile significantly. However, the lack of difference could also be due to the diet composition, which is found to have a large effect on microbial profile, by the modulation of physico-chemical properties and nutrient supply for specific microflora growth [22]. As all of the diets were formulated with approximately $40 \%$ wheat, $30 \%$ maize, and $20 \%$ soybean meal (Table 1 ), and although the dose rate of the multienzyme was increased $(0 \mathrm{~g} / \mathrm{t}, 350 \mathrm{~g} / \mathrm{t}, 700 \mathrm{~g} / \mathrm{t}$, and $1000 \mathrm{~g} / \mathrm{t})$, the dietary composition was not changed, therefore, the same microbial consortia would proliferate in the same relative proportion in each treatment group.

There were three bacteria unique to a particular Natuzyme dose rate (Figure 5). Romboutsia spp. and Ruminococcus gauvreauii were isolated from $700 \mathrm{~g} / \mathrm{t}$ Natuzyme. Ruminococcus has been reported to be positively correlated with good feed efficiency in broiler chickens, as this genus is known for its ability to degrade complex carbohydrates 
and fibers [26]. As work on these species has not been conducted in poultry, mapping of the human intestinal microbiome demonstrates that Romboutsia spp. is present in nutrient-rich environments where exogenous sources of amino acids and vitamins are abundantly available [27]. Whilst there is limited literature on this species functionality in poultry, the carbon sources it utilizes include D-arabinose, L-fucose, D-galactose, D-glucose, raffinose, and sucrose and it can produce acetate and formate [27]. This suggests a possible role in gut health promotion as it could modulate inflammation and oxidative stress [28,29]. The multienzyme nature of Natuzyme releases vitamins and minerals that are bound to compounds inaccessible by endogenous enzymes alone, such as protease, increasing protein digestibility, and phytase, increasing calcium, phosphorus, and zinc availability. Therefore, the presence of this species should not be surprising in super-dosed diets, however, this species did not appear in the D10 (1000 g/t Natuzyme) microbiome, but it remains unclear as to why. Further research is required on the role of Romboutsia spp. and Ruminococcus gauvreauii in the poultry digestive system. Similarly, Barnesiella spp. isolated from $1000 \mathrm{~g} / \mathrm{t}$ Natuzyme has been reported to be one of the core cecal lumen bacteria and may contribute to hydrolyzing starch and other macromolecules, short-chain fatty acid formation, and feed conversion in broiler chicken [30]. Similarly, to Romboustia spp., the production of short chain fatty acids (SCFAs) could further promote gut health through the modulation of various immune-related host biological responses. Further studies are required on these species to ascertain their role in poultry digestive systems.

\subsection{Nutrient Digestibility}

The apparent ileal digestibility of nutrients is a direct indicator of bird health and gut functionality. In particular, the improvement of nutrient digestibility is commonly accompanied by an improvement in gut morphology, such as longer villi, which improves the surface area to volume ratio, thus enabling a wider surface for nutrients to absorb across. The results of the present study revealed significant improvement $(p \leq 0.001)$ in nutrient digestibility with increasing Natuzyme dose rates (Table 7).

As aforementioned, the primary enzymes in the formulation are phytase, xylanase, amylase, beta-glucanase, protease, and mannanase, thus it is a broad-spectrum application to feed, hence a significant increase in digestibility. The diets were approximately $40 \%$ wheat, $30 \%$ soybean meal, and $20 \%$ corn (Table 1 ) and combined, maize and wheat contain approximately $12 \%$ arabinoxylans, which are an antinutritional factor that increase intestinal viscosity which limits the absorption of nutrients in broiler chickens $[7,31]$. Incorporating xylanase and beta-glucanase into the diet enables a reduction in intestinal viscosity and eliminates the encapsulating effects of the non-starch polysaccharides in the gut and therefore a great overall improvement in nutrient digestibility. Soybean meal contains trypsin inhibitors, which block the degradation of protein, thus decreasing overall availability of protein in the diet [32], while corn and wheat contain phytic acid, which limits the bioavailability of phosphorus, calcium, zinc, and some amino acids [7]. Natuzyme contains protease, which alleviates the effect of trypsin inhibitors in soybean meal and improves protein hydrolysis in the presence of trypsin and therefore increases the digestible protein content of the diet [6]. Additionally, Natuzyme contains phytase, which breaks the bond between phytic acid, phosphorus, calcium, and zinc to increase mineral bioavailability, hence the significant improvement in nutrient digestibility in enzyme compared to no enzyme addition groups (Table 7) [33]. Similar results to those obtained in the present study are well recorded in the literature, with [33-35] demonstrating an improvement in overall digestibility when incorporating multienzymes into broiler diets.

\subsection{Bone Mineralization}

Bone mineral content and ash are good indicators of mineral utilization efficiency. It was expected that the multienzyme super-dosing may improve bone ash and mineral content. Our results, however, showed no differences in the tibia bone ash and mineral content when Natuzyme was included in the control diet at increasing dose rates. Our results are in 
line with the reports by Hajimohammadi et al. [36], who did not find significant differences in relative weight, length, density, and ash percentage of tibia bone when phytase was added to the negative control at 42 days of age. However, these outcomes are not in line with previous studies that have reported enhanced bone calcium and phosphorous content when phytase was supplemented in the negative control [37]. Similarly, Dilger et al. [38] and Francesch and Geraert [39] reported enhanced tibia ash and bone mineralization with phytase addition in the negative control diet. In our study, dietary calcium and phosphorous content was at the recommended level (positive control) and this might be a reason for the lack of response to multienzyme addition. The previous studies used negative control and positive control diets and the enzyme addition restored the bone mineral content of the birds in a similar way to the positive control [37-39].

\section{Conclusions}

This study aimed to ascertain whether super-dosing multienzymes would improve gut morphology, change the cecal microbial profile, and improve nutrient digestibility in broiler chickens. Results revealed that Natuzyme super-dosing tended to improve gut morphology, and significantly enhanced nutrient digestibility. The microbial profile was not significantly altered by increasing the Natuzyme dose rate, however, three bacterial species were unique to a higher level of Natuzyme in the diet. It was concluded that a dose of $700 \mathrm{~g} / \mathrm{t}$ could be recommended to optimize gut morphology, nutrient digestibility, and support gut microbial diversity. Further investigations are required to study the functions and roles of Romboutsia spp., Ruminococcus gauvreauii, and Barnesiella spp. in the poultry digestive system and identify potential links between these species and improved feed utilization and efficiency.

Supplementary Materials: The following are available online at https:/ / www.mdpi.com/2076-261 5/11/1/1/s1, Figure S1: Rarefaction plot indicating total number of sequenced reads per sample and richness.

Author Contributions: Conceptualization, E.A.S. and J.M.-S.; Data curation, E.A.S., J.M.-S., and D.M.; Formal analysis, E.A.S., J.M.-S., and D.M.; Investigation, E.A.S. and J.M.-S.; Methodology, E.A.S. and J.M.-S.; Supervision, E.A.S.; Writing-original draft, J.M.-S.; Writing—review and editing, E.A.S., J.M.-S., and D.M.; Funding acquisition, E.A.S. All authors have read and agreed to the published version of the manuscript.

Funding: This work was supported by Bioproton Pty. Ltd., QLD Australia and School of Agriculture and Food Science, University of Queensland, QLD, Australia.

Acknowledgments: We would like to acknowledge Shahram Niknafs for technical assistance, and Bwalya Nkole and Darwin Horyanto for their assistance on the farm.

Conflicts of Interest: Deirdre Mikkelsen declares no conflict of interest. Elham Assadi Soumeh has received funding from Bioproton Pty Ltd. to conduct the trial. Jacoba Madigan-Stretton declares that she works for Bioproton Pty Ltd.

\section{References}

1. Xu, J.; Gordon, J.I. Honor thy symbionts. Proc. Natl. Acad. Sci. USA 2003, 100, 10452-10459. [CrossRef] [PubMed]

2. Xu, J.; Mahowald, M.A.; Ley, R.E.; Lozupone, C.A.; Hamady, M.; Martens, E.C.; Henrissat, B.; Coutinho, P.M.; Minx, P.; Latreille, P.; et al. Evolution of Symbiotic Bacteria in the Distal Human Intestine. PLoS Biol. 2007, 5, e156. [CrossRef] [PubMed]

3. Choct, M. Managing gut health through nutrition. Br. Poult. Sci. 2009, 50, 9-15. [CrossRef] [PubMed]

4. Barug, D.; De Jong, J.; Kies, A.K.; Verstegen, A.M.W.A. Antimicrobial Growth Promoters, 1st ed.; Wageningen Academic Publishers: Wageningen, The Netherlands, 2006; pp. 19-51.

5. Waxenecker, F. The Impact of Gut Health and Gut Integrity on Performance of Livestock Animals. Available online: https: //www2.biomin.net/ (accessed on 22 November 2020).

6. Dosković, V.; Bogosavljević-Bosković, S.; Pavlovski, Z.; Milošević, B.; Škrbić, Z.; Rakonjac, S.; Petričević, V. Enzymes in broiler diets with special reference to protease. World's Poult. Sci. J. 2013, 69, 343-360. [CrossRef]

7. Bedford, M.; Partridge, G. Enzymes in Farm Animal Nutrition, 2nd ed.; CABI: Wallingford, UK; Cambridge, MA, USA, 2010; pp. 1-10. 
8. Uni, Z.; Noy, Y.; Sklan, D. Posthatch development of small intestinal function in the poultry. Poult. Sci. J. 1999, 78, $215-222$. [CrossRef]

9. Law, F.L.; Idrus, Z.; Farjam, A.S.; Boo, L.J.; Awad, E.A. Effects of protease supplementation of low protein and/or energy diets on growth performance and blood parameters in broiler chickens under heat stress condition. Ital. J. Anim. Sci. 2019, 18, 679-689. [CrossRef]

10. Hamdi, M.; Pérez, J.; Létourneau-Montminy, M.-P.; Franco-Rosselló, R.; Aligue, R.; Solà-Oriol, D. The effects ofmicrobial phytases and dietary calcium and phosphorus levels on the productive performance and bone mineralization of broilers. Anim. Feed. Sci. Technol. 2018, 243, 41-51. [CrossRef]

11. Cowieson, A.J.; Wilcock, P.; Bedford, M.R. Super-dosing effects of phytase in poultry and other monogastrics. World's Poult. Sci. J. 2011, 67, 225-236. [CrossRef]

12. Bolyen, E.; Rideout, J.R.; Dillon, M.R.; Bokulich, N.A.; Abnet, C.C.; Al-Ghalith, G.A.; Alexander, H.; Alm, E.J.; Arumugam, M.; Asnicar, F.; et al. Reproducible, interactive, scalable and extensible microbiome data science using QIIME 2. Nat. Biotechnol. 2019, 37, 852-857. [CrossRef]

13. McDonald, D.; Price, M.N.; Goodrich, J.K.; Nawrocki, E.P.; DeSantis, T.Z.; Probst, A.J.; Andersen, G.L.; Knight, R.; Hugenholtz, P. An improved Greengenes taxonomy with explicit ranks for ecological and evolutionary analyses of bacteria and archaea. ISME J. 2011, 6, 610-618. [CrossRef]

14. Zakrzewski, M.; Proietti, C.; Ellis, J.J.; Hasan, S.; Brion, M.-J.; Berger, B.; Krause, L. Calypso: A user-friendly web-server for mining and visualizing microbiome-environment interactions. Bioinformatics 2016, 33, 782-783. [CrossRef] [PubMed]

15. AOAC. Official Methods of Analysis in Association of Official Analytical Chemists; AOAC International: Arlington, VA, USA, 2005.

16. Scott, T.A.; Hall, J.W. Using acid insoluble ash marker ratios (diet:digesta) to predict digestibility of wheat and barley metabolizable energy and nitrogen retention in broiler chicks. Poult. Sci. 1998, 77, 674-679. [CrossRef] [PubMed]

17. SAS Institute Inc. SAS User's Guide. Statistics; Version 9.1; SAS Institute Inc.: Cary, NC, USA, 2003.

18. Magurran, A.E. Measuring Biological Diversity; Blackwell-Wiley: Malden, MA, USA, 2013.

19. Sharifi, S.D.; Golestani, G.; Yaghobfar, A.; Khadem, A.; Pashazanussi, H. Effects of supplementing a multienzyme to broiler diets containing a high level of wheat or canola meal on intestinal morphology and performance of chicks. J. Appl. Poult. Res. 2013, 22, 671-679. [CrossRef]

20. Ahmed, H.; El-Toukhey, N.; Attia, K.; El-Samannoudy, S. Effect of Multienzymes and Absorption Enhancers on Productive Performance, Gut Morphology and Some Blood Biochemical and Hormonal Parameters in Broiler Chicks. J. Agric. Sci. 2013, 5, 162-179. [CrossRef]

21. Mazhari, M.; Golian, A.; Kermanshahi, H. Effect of corn replacement with graded levels of wheat screening and enzyme supplementation on performance, blood lipids, viscosity and jejunal histomorphology of finisher broilers. Span. J. Agric. Res. 2015, 13, e0603. [CrossRef]

22. Shakouri, M.D.; Iji, P.A.; Mikkelsen, L.L.; Cowieson, A.J. Intestinal function and gut microflora of broiler chickens as influenced by cereal grains and microbial enzyme supplementation. J. Anim. Physiol. Anim. Nutr. 2009, 93, 647-658. [CrossRef] [PubMed]

23. Teirlynck, E.; Bjerrum, L.; Eeckhaut, V.; Huygebaert, G.; Pasmans, F.; Haesebrouck, F.; Dewulf, J.; Ducatelle, R.; Van Immerseel, F. The cereal type in feed influences gut wall morphology and intestinal immune cell infiltration in broiler chickens. Br. J. Nutr. 2009, 102, 1453-1461. [CrossRef]

24. Lourenco, J.M.; Nunn, S.C.; Lee, E.J.; Dove, C.R.; Callaway, T.R.; Azain, M.J. Effect of Supplemental Protease on Growth Performance and Excreta Microbiome of Broiler Chicks. Microorganisms 2020, 8, 475. [CrossRef]

25. Danzeisen, J.L.; Kim, H.B.; Isaacson, R.E.; Tu, Z.J.; Johnson, T.J. Modulations of the Chicken Cecal Microbiome and Metagenome in Response to Anticoccidial and Growth Promoter Treatment. PLoS ONE 2011, 6, e27949. [CrossRef]

26. Siegerstetter, S.-C.; Schmitz-Esser, S.; Magowan, E.; Wetzels, S.U.; Zebeli, Q.; Lawlor, P.G.; O'Connell, N.E.; Metzler-Zebeli, B.U. Intestinal microbiota profiles associated with low and high residual feed intake in chickens across two geographical locations. PLoS ONE 2017, 12, e0187766. [CrossRef]

27. Gerritsen, J.; Hornung, B.; Ritari, J.; Paulin, L.; Rijkers, G.; Schaap, P. A comparative and functional genomics analysis of the genus Romboutsia provides insight into adaptation to an intestinal lifestyle. bioRxiv 2019, 845511. [CrossRef]

28. Tan, J.; McKenzie, C.; Potamitis, M.; Thorburn, A.N.; Mackay, C.R. Chapter three-The role of short-chain fatty acids in health and disease. Adv. Immunol. 2014, 121, 91-119. [PubMed]

29. Huang, W.; Guo, H.-L.; Deng, X.; Zhu, T.-T.; Xiong, J.-F.; Xu, Y.-H.; Xu, Y. Short-Chain Fatty Acids Inhibit Oxidative Stress and Inflammation in Mesangial Cells Induced by High Glucose and Lipopolysaccharide. Exp. Clin. Endocrinol. Diabetes 2017, 125, 98-105. [CrossRef] [PubMed]

30. Pandit, R.J.; Hinsu, A.T.; Patel, N.V.; Koringa, P.G.; Jakhesara, S.J.; Thakkar, J.R.; Shah, T.M.; Limon, G.; Psifidi, A.; Guitian, J.; et al. Microbial diversity and community composition of caecal microbiota in commercial and indigenous Indian chickens determined using 16s rDNA amplicon sequencing. Microbiome 2018, 6, 1-13. [CrossRef]

31. Saulnier, L.; Sado, P.-E.; Branlard, G.; Charmet, G.; Guillon, F. Wheat arabinoxylans: Exploiting variation in amount and composition to develop enhanced varieties. J. Cereal Sci. 2007, 46, 261-281. [CrossRef]

32. Hill, G.D. Plant Antinutritional Factors. Characteristics. In Encyclopedia of Food Sciences and Nutrition; Caballero, B., Finglas, P., Toldra, F., Eds.; Academic Press: San Diego, CA, USA, 2003; pp. 4578-4587. 
33. Selle, P.H.; Ravindran, V.; Caldwell, A.; Bryden, W.L. Phytate and phytase: Consequences for protein utilisation. Nutr. Res. Rev. 2000, 13, 255-278. [CrossRef]

34. Stefanello, C.; Vieira, S.; Santiago, G.O.; Kindlein, L.; Sorbara, J.O.B.; Cowieson, A.J. Starch digestibility, energy utilization, and growth performance of broilers fed corn-soybean basal diets supplemented with enzymes. Poult. Sci. 2015, 94, $2472-2479$. [CrossRef]

35. Kaczmarek, S.A.; Rogiewicz, A.; Mogielnicka, M.; Rutkowski, A.; Jones, R.O.; Slominski, B.A. The effect of protease, amylase, and nonstarch polysaccharide-degrading enzyme supplementation on nutrient utilization and growth performance of broiler chickens fed corn-soybean meal-based diets. Poult. Sci. 2014, 93, 1745-1753. [CrossRef]

36. Hajimohammadi, A.; Mottaghitalab, M.; Hashemi, M. Effects of microbial fermented sesame meal and enzyme supplementation on the intestinal morphology, microbiota, $\mathrm{pH}$, tibia bone and blood parameters of broiler chicks. Ital. J. Anim. Sci. 2020, 19, 457-467. [CrossRef]

37. Zeng, Q.; Huang, X.; Luo, Y.; Ding, X.; Bai, S.; Wang, J.; Xuan, Y.; Su, Z.; Liu, Y.G.; Zhang, K. Effects of a multi-enzyme complex on growth performance, nutrient utilization and bone mineralization of meat duck. J. Anim. Sci. Biotechnol. 2015, 6, 12. [CrossRef]

38. Dilger, R.N.; Onyango, E.M.; Sands, J.S.; Adeola, O. Evaluation of Microbial Phytase in Broiler Diets. Poult. Sci. 2004, 83, 962-970. [CrossRef] [PubMed]

39. Francesch, M.; Geraert, P.A. Enzyme complex containing carbohydrases and phytase improves growth performance and bone mineralization of broilers fed reduced nutrient corn-soybean-based diets. Poult. Sci. 2009, 88, 1915-1924. [CrossRef] [PubMed] 